\title{
Nutritional support in chronic obstructive lung disease
}

\section{Why?}

In the last decade increasing attention has been focused on nutritional problems in respiratory disorders, and particularly in chronic obstructive lung disease. This stems from an awareness that malnutrition is an important clinical problem in a subpopulation of patients with chronic obstructive lung disease. The picture of the emaciated emphysematous patient, or pink puffer, is known to every clinician. This common perception is substantiated by several reports. ${ }^{1-12}$ In a study from the United States National Institutes of Health on the effects of intermittent positive pressure breathing nearly a quarter of 779 men with stable chronic obstructive lung disease weighed less than $90 \%$ of their ideal body weight, a simple albeit imperfect index of malnutrition. ${ }^{11}$ The prevalence of malnutrition increases with the severity of airways obstruction, ${ }^{2411}$ and approduches or excects $50 \%$ in series of patients admitted forospital. "Moreover, several studtics in the 1960s showed that malnutrition in itself contributed to mortality. ${ }^{3513}$ The more recent National Institutes of Health trial also showed that mortality was higher in malnourished patients, independently of the severity of airways obstruction. ${ }^{11}$ Reduced respiratory muscle mass and function, as well as increased susceptibility to infection, ${ }^{+8}$ are recognised as deleterious consequences of malnutrition.

Because malnutrition appears to be common and life threatening in patients with chronic obstructive lung disease, the iderof providing them with nutritionat support has logically emerged. Several questions need to be answered, however, before nutritional support can be efficiently implemented.

\section{How much?}

The question of how much energy needs to be provided perhaps depends on the mechanism of weight loss in chronic obstructive lung disease: is this due to reduced energy intake or to increased energy output? Earlier studies, based on dietary histories, showed that the energy intake of malnourished patients with chronic obstructive lung disease was either adequate in relation to the recommended daily allowances or at least similar to that of well nourished patients. 9919 Using indirect calorimetry, however, several groups have recently reported a $10-20 \%$ increase in resting energy expenditure in patients with stable chronic obstructive lung disease. ${ }^{20-25}$ This excessive energy expenditure contrasts with the reduced metabolic rate usually observed in matrutrition and has been attributed to the increased cost of breathing. ${ }^{22}$ According to these findings, weight loss would seem to be the consequence of increased energy output rather than of reduced intake. Despite a higher resting energy expenditure, however, total energy expenditure was found to be normal in patients, as measured during 24 hours in a metabolic chamber. ${ }^{26}$ Spontaneously reduced physical activity could save energy in these patients and compensate for their resting hypermetabolism. Thus weight loss probably results primarily from inadequate energy intake in relation to energy needs, which is likely to occur during many exacerbations of the disease.

How much support is necessary also depends on the metabolic response to nutritional supplementation. Hypermetabolism caused by stress, burns, or injuriés commonly requires a very high energy and nitrogen intake to stabilise nitrogen retention. Although hypermetabolic at rest, malnourished patients with chronic obstructive lung disease achieve a positive nitrogen balance when energy intake is adequate for expenditure. ${ }^{20}$ Thus they react like nutritionally depleted individuals and should theoretically benefit from nutritional support.

Several controlled studies have assessed the effect of nutritional support in chronic obstructive lung disease, either in outpatients ${ }^{27-30}$ or in inpatients. ${ }^{31}$ In addition to changes in nutrition, the peripheral and respiratory muscle performance and exercise capacity have been evaluated. The outcome of these studies was directly related to the actual increment in energy intake. Weight gain could be achieved only by substantialty-increasing energy intake, by more than $30 \%$ above the usual intake, amounting to more than $45 \mathrm{Kcal}(0 \cdot 19 \mathrm{MJ}) / \mathrm{kg}$ per day. Moreover, improvement in muscte function or exercise tolerance occurred only with concomitant weight gain.

In one of these controlled studies oral supplementation was given for three months to ambulatory malnourished patients with chronic obstructive lung disease. Daily energy intake increased by $48 \%$ above the usual intake and corresponded to $47 \mathrm{kcal}(0 \cdot 196 \mathrm{MJ}) / \mathrm{kg}$ on average. The authors reported a mean weight gain of $4.2 \mathrm{~kg}$, an incrase in maximal respiratory pressures and in handgrip and sternomastoid strength, and a decrease in sternomastoid muscle fatigability; similar improvements were not observed in a control group. Unfortunately these improvements waned or disappeared once the patients had returned to their usual diet. In another study six malnourished patients with chronic obstructive lung disease received nocturnal supplemental feeding via a nasoenteric tube for 16 days. Energy intake increased by $75 \%$ above the usual and corresponded to $49 \cdot 5 \mathrm{kcal}(0 \cdot 207 \mathrm{MJ}) / \mathrm{kg}$ a day on average. Body weight increased by $2.4 \mathrm{~kg}$ and was accompanied by an improvement in respiratory muscle strength and endurance. None of these changes occurred in four similar patients receiving sham supplementation. ${ }^{31}$ In contrast, no change in weight or muscle performance was observed in patients whose increment in energy intake was smaller. ${ }^{27} 2830$ 
What?

The composition of nutritional supplementation for patients with lung disease has received some attention. Carbon dioxide production $\left(\mathrm{V}_{\mathrm{CO}}\right)$ is higher when carbohydrates are the main energy sources and lower when fat is mainly oxidised. Thus the respiratory quotient $\left(\mathrm{RQ}=\dot{\mathrm{V}} \mathrm{CO}_{2} / \dot{\mathrm{VO}}_{2}\right)$ tends towards 1.0 with carbohydrate based diets and towards 0.7 with fat based diets. For arterial carbon dioxide tension $\left(\mathrm{PaCO}_{2}\right)$ to remain constant an increased $\mathrm{VCO}_{2}$ Is dependen on an increase in alven ar ventilation. Thus carbohydrate loads could induce or worsen hypercapnia in patients with severe ventilatory limitation. This has been observed with high energy supplements administered to patients during mechanical ventilation or weaning. ${ }^{32} 33$

Patients with chronic obstructive lung disease who are in a stable clinical state, however, usually appear to tolerate carbohydrates without difficulty. At rest both normocapnic and hypercapnic patients were able to maintain a constant $\mathrm{PaCO}_{2}$ after a $920 \mathrm{kcal}(3.85 \mathrm{~J})$ carbohydrate load. ${ }^{34}$ No clinicallyssignificant difference could be noted with low or high carbohydrate diets in a group of hypercapintc patients with chronic obstructive lung disease. ${ }^{35}$ Furthermore, respiratory failure was not reported in stable patients while they were-receiving nutritiona support, even with-diet formulas containing up to $54 \%$ carbohydrates. ${ }^{20}$ 27-31 36 Thus low carbohydrate, high fat formulas do not seem necessary for nutritional support in patients with stable chronic obstructive lung disease.

\section{How?}

The failure of nutritional support that was observed in some trials conducted in patients with chronic obstructive lung disease seems mainly due to the inability of the patients to increase their energy intake sufficiently. ${ }^{27} 2830$ Spontaneous reduction in the usual energy intake and intolerance of supplemental formulas were frequently encountered. Nocturnal supplemental feeding via a nasoenteric tube may obviate these difficulties and proved to be effective in inpatients. ${ }^{31}$ When oral supplements are used they should be given at the end of meals or between meals so that the usual dietary intake is maintained. Both inpatients and outpatients must have close monitoring and counselling if they are to maintain their energy intake and learn various strategies for coping with meal related complaints such as anorexia, early satiety, bloating, and dyspnoea. ${ }^{37}$ From these recent trials, nutritional intêrvention appears to be feasible but difficult in chronic obstructive lung disease, requiring dedicated and specialised personnel.

\section{For whom?}

At the moment we know several things about nutritional deficiency in chronic obstructive lung disease. Firstly, malnutrition is known to represent an important clinical problem, with its high prevalence and its aggravating influence on mortality. Secondly, we are beginning to understand the disruption of energy balance that leads to weight loss in these patients. Thirdly, malnutrition has been shown to be improved by nutritional intervention. Finally, we know how nutritional support should be provided in chronic obstructive lung disease, and also that it represents a major undertaking.

We still lack some important information, however. Firstly, if nutritional support appears intuitively logical for patients with chronic obstructive lung disease its impact on morbidity, quality of life, number of hospital admissions, and mortality has yet to be seen. Once this has been done it will be essential to define selection criteria to recognise those patients likely to benefit from nutritional support. Because of the labour and cost required this intervention should not be applied indiscriminately. These questions need to be answered and a cost-benefit analysis must be performed before nutritional support can be recommended on a wide scale in chronic obstructive lung disease.

JEAN-WILLIAM FITTING

Division de Pneumologie,

Centre Hospitalier Universitaire Vaudois,

1011 Lausanne,

Switzerland

Reprint requests to: Dr Fitting

1 Mitchell RS, Filley GF. Chronic obstructive bronchopulmonary disease. I. Clinical features. Am Rev Respir Dis 1964;89:360-71.

2 Burrows B, Niden AH, Barclay WR, Kasik JE. Chronic obstructive lung disease. II. Relationship of clinical and physiologic findings to the severity of airways obstruction. Am Rev Respir Dis 1964;91:665-78.

3 Sukumalchantra $Y$, Williams $M H$. Serial studies of pulmonary function in patients with chronic obstructive pulmonary disease. Am J Med 1965;39:941-5.

4 Renzetti AD, McClement JH, Litt BD. The veterans administration cooperative study of pulmonary function. III. Mortality in relation to respiratory function in chronic obstructive pulmonary disease. $\mathrm{Am} \mathrm{J} \mathrm{Med}$ 1966;41:115-29.

5 Vandenbergh E, Van de Woestijne KP, Gyselen A. Weight changes in the terminal stages of chronic obstructive pulmonary disease. Am Rev Respir Dis 1967;95:556-65.

6 Hunter AMB, Carey MA, Larsh HW. The nutritional status of patients with chronic obstructive pulmonary disease. Am Rev Respir Dis 1981;124 376-81.

7 Driver AG, McAlevy MT, Smith JL. Nutritional assessment of patients with chronic obstructive pulmonary disease and acute respiratory failure. Chest 1982;82:568-71

8 Openbrier DR, Irwin MM, Rogers RM, Gottlieb GP, Dauber JH, Van Thiel DH, et al. Nutritional status and lung function in patients with emphysema and chronic bronchitis. Chest 1983;83:17-22.

9 Braun SR, Keim NL, Dixon RM, Clagnaz P, Anderegg A, Shrago ES. The prevalence and determinants of nutritional changes in chronic obstructive pulmonary disease. Chest 1984;86:558-63.

10 Fiaccadori E, Del Canale S, Coffrini E, Vitali P, Antonucci C, Cacciani G, et al. Hypercapnic-hypoxemic chronic obstructive pulmonary disease (COPD): influence of severity of COPD on nutritional status. Am J Clin Nutr 1988;48:680-5.

11 Wilson DO, Rogers RM, Wright EC, Anthonisen NR. Body weight in chronic obstructive pulmonary disease. The National Institutes of Health intermittent positive-pressure breathing trial. Am Rev Respir Dis 1989;139:1435-8

12 Schols A, Mostert R, Soeters P, Greve LH, Wouters EFM. Inventory of nutritional status in patients with COPD. Chest 1989;96:247-9.

13 Boushy SF, Adhikari PK, Sakamoto A, Lewis BM. Factors affecting prognosis in emphysema. Dis Chest 1964;45:402-11.

14 Thurlbeck WM. Diaphragm and body weight in emphysema. Thorax 1978;33:483-7.

15 Arora NS, Rochester DF. Effect of body weight and muscularity on human diaphragm muscle mass, thickness, and area. J Appl Physiol 1982;52: 64-70.

16 Rochester DF, Braun NMT. Determinants of maximal inspiratory pressure in chronic obstructive pulmonary disease. Am Rev Respir Dis 1985; 132:42-7.

17 Gray-Donald K, Gibbons L, Shapiro SH, Martin JG. Effect of nutritional status on exercise performance in patients with chronic obstructive pulmonary disease. Am Rev Respir Dis 1989;140:1544-8.

18 Niedermann MS, Merrill WW, Ferranti RD, Pagano KM, Palmer LB, Reynolds HY. Nutritional status and bacterial binding in the lower respiratory tract in patients with chronic tracheostomy. Ann Intern Med 1984;100:795-800.

19 Openbrier DR, Irwin MM, Dauber JH, Owens G, Rogers RM. Factors affecting nutritional status and the impact of nutritional support in patients with emphysema. Chest 1984;85:67-9S.

20 Goldstein SA, Thomashow BM, Kvetan V, Askanazi J, Kinney JM, Elwyn $\mathrm{DH}$. Nitrogen and energy relationships in malnourished patients with emphysema. Am Rev Respir Dis 1988;138:636-44.

21 Fitting JW, Frascarolo $\mathrm{Ph}$, Jéquier E, Leuenberger $\mathrm{Ph}$. Energy expenditure and rib cage-abdominal motion in chronic obstructive pulmonary disease. Eur Respir J 1989;2:840-5.

22 Donahoe M, Rogers RM, Wilson DO, Pennock BE. Oxygen consumption of the respiratory muscles in normal and in malnourished patients with chronic obstructive pulmonary disease. Am Rev Respir Dis 1989;140: 385-91.

23 Wilson DO, Donahoe M, Rogers RM, Pennock BE. Metabolic rate and weight loss in chronic obstructive lung disease. Journal of Parenteral and Enteral Nutrition 1990;14:7-11.

24 Lanigan C, Moxham J, Ponte J. Effect of chronic airflow limitation on resting oxygen consumption. Thorax 1990;45:388-90.

25 Schols AMWJ, Soeters PB, Mostert R, Saris WHM, Wouters EFM. Energy balance in chronic obstructive pulmonary disease. Am Rev Respir Dis 1991;143:1248-52.

26 Hugli $O$, Schutz Y, Leuenberger Ph, Fitting JW. The daily energy expenditure of COPD patients in confined and free-living condition [abstract]. Am Rev Respir Dis 1991;143:A453. 
27 Lewis MI, Belman MJ, Door-Uyemura L. Nutritional supplementation in ambulatory patients with chronic obstructive pulmonary disease. Am Rev Respir Dis 1987;135:1062-8.

28 Knowles JB, Fairbarn MS, Wiggs BJ, Chan-Yan C, Pardy RL. Dietary supplementation and respiratory muscle performance in patients with COPD. Chest 1988;93:977-83.

29 Efthimiou J, Fleming J, Gomes C, Spiro SG. The effect of supplementary oral nutrition in poorly nourished patients with chronic obstructive pulmonary disease. Am Rev Respir Dis 1988;137:1075-82.

30 Otte KE, Ahlburg P, D'Amore F, Stellfeld $M$. Nutritional repletion in malnourished patients with emphysema. Journal of Parenteral and Enteral Nutrition 1989;13:152-6.

31 Whittaker JS, Ryan CF, Buckley PA, Road JR. The effects of refeeding on peripheral and respiratory muscle function in malnourished chronic obstructive pulmonary disease patients. Am Rev Respir Dis 1990;142: 283-8.
32 Covelli HD, Waylon Black J, Olsen MS, Beekman JF. Respiratory failure precipitated by high carbohydrate loads. Ann Intern Med 1981;95:579-81. 33 Dark DS, Pingleton SK, Kerby GR. Hypercapnia during weaning. A complication of nutritional support. Chest 1985;88:141-3.

34 Gieseke T, Gurushanthaiah G, Glauser FL. Effects of carbohydrates on carbon dioxide excretion in patients with airway disease. Chest 1977;71:55-8.

35 Angelillo VA, Bedi S, Durfee D, Dahl J, Patterson AJ, O'Donohue WJ. Effects of low and high carbohydrate feedings in ambulatory patients with chronic obstructive pulmonary disease and chronic hypercapnia. Ann chronic obstructive pulmonar.

36 Wilson DO, Rogers RM, Sanders MH, Pennock BE, Reilly JJ. Nutritional intervention in malnourished patients with emphysema. Am Rev Respir Dis 1986;134:672-7.

37 Donahoe M, Rogers RM. Nutritional assessment and support in chronic obstructive pulmonary disease. Clin Chest Med 1990;11:487-504.

\section{Editorial note}

\section{Supplements for Thorax}

The British Medical Journal Publishing Group (which is the co-owner of Thorax with the British Thoracic Society) is willing to consider publishing supplements to the regular issues of Thorax. The British Thoracic Society executive committee has supported these proposals and has granted permission for Thorax to publish up to four supplements a year.

The purpose of these supplements would be to deal in depth with important or "hot" topics. They might also originate from a meeting on a particular topic organised by the editor or editorial board or a learned society. A sponsoring organisation, often a pharmaceutical company, that wishes to arrange a symposium may plan to have the proceedings published as a supplement. The venture of supplements has been successful in other journals, and we believe that this is a step forward for Thorax.
Supplements will be considered for publication only when their contents are unbiased and of educational value or a professional service to readers-that is, where the contents have quality and independence. No supplements that would be merely for promotional purposes will be considered. Papers will be considered for publication only if they deal with original work or review previous studies. Any supplement submitted will be subjected to editorial review by the editor of Thorax or an elected member of the editorial organisation.

An initial request to commission a supplement should always be either to the editor of Thorax or to the specialist journals publishing director of the $B M J$.

STEPHEN SPIRO 